\title{
DESIGUALDAD, ELITES Y ENCUENTRO. ALGUNOS DESAFÍOS PARA LA COHESIÓN SOCIAL EN CHILE*
}

\author{
Catalina Siles \\ Instituto de Estudios de la Sociedad
}

\begin{abstract}
RESUMEN: Este artículo arguye que la desigualdad se ha convertido en uno de los principales desafíos para la cohesión social en Chile. De acuerdo a la literatura que se cita, las aspiraciones democráticas modernas exigen, entre otras cosas, cierta equidad en la distribución de los bienes socialmente relevantes, de modo tal que todos los ciudadanos puedan sentirse parte de un proyecto comunitario. Bajo el punto de vista de la autora, el proceso de modernización chileno de las últimas décadas, si bien ha logrado significativos avances en muchas materias, no ha alcanzado resultados trascendentes en la disminución de la desigualdad, la que presenta nuevas formas y características. Esta desigualdad, entre sus consecuencias, provocaría el distanciamiento de las elites del resto del entramado social, con efectos en los vínculos sociales que articulan la comunidad política.
\end{abstract}

Palabras Clave: cohesión social, modernización, desigualdad, elites. RECIBIDO: noviembre 2017; ACEPTADO: marzo 2018.

Catalina Siles. Historiadora de la Universidad de los Andes. Magíster en historia por la Pontificia Universidad Católica y estudiante del doctorado en sociología en la misma institución. Investigadora del Instituto de Estudios de la Sociedad (IES). Email: csiles@ieschile.cl.

* La autora agradece los comentarios y sugerencias de los árbitros anónimos y editores de Estudios Públicos, y particularmente al equipo del IES, en especial a Claudio Alvarado, Josefina Araos, Daniel Mansuy, Santiago Ortúzar, Josefina Poblete y Manfred Svensson por su colaboración en las distintas etapas de este artículo. 


\title{
INEQUALITY, ELITES AND COMMON GROUND. SOME CHALLENGES FOR SOCIAL COHESION IN CHILE
}

\begin{abstract}
This article argues that inequality has become one of the main challenges for social cohesion in Chile. According to the literature cited, one of the things that modern democratic aspirations require is a degree of equity in the distribution of socially important goods so that all citizens can feel part of a community project. As the author sees it, while the modernization process of recent decades in Chile has brought about substantial advances in many areas, it has not achieved a significant reduction in inequality, with this having taken on new forms and characteristics. She argues that one of the consequences of this inequality has been the distancing of elites from the rest of the social fabric, with effects on the social ties that go to form the political community
\end{abstract}

KEYWORDS: social cohesion, modernization, inequality, elites.

RECEIVED: November 2017; ACCEPTED: March 2018.

Mientras más parecidas llegan a ser las condiciones, tanto más manifiestan los hombres esta disposición recíproca a ayudarse.

Alexis de Tocqueville, La democracia en América ${ }^{1}$

\section{INTRODUCCIÓN}

- egún Tocqueville, la modernidad supuso, entre otras cosas, una transformación de los vínculos sociales. ${ }^{2}$ El nuevo orden social, que impulsó la revolución democrática, modificó los fundamentos de la cohesión de nuestras sociedades, que debían resolverse ahora bajo una nueva lógica. Así, para el pensador francés, la democracia consistía fundamentalmente en el "desarrollo gradual y progresivo de la igualdad". 3 Y era, por tanto, este principio el que debía sustentar las nuevas estructuras y formas de organización de nuestras sociedades.

Este movimiento democrático, tal como lo anticipó Tocqueville, ha sido ambivalente. La progresiva complejización de la sociedad, los

${ }^{1}$ Alexis de Tocqueville, La Democracia en América (Madrid: Ediciones Akal, 2007), vol. II, parte III, cap. 4.

${ }^{2}$ Alexis de Tocqueville, La democracia en América.

${ }^{3}$ Ibídem, "Introducción", 37. 
procesos de individuación, la expansión del Estado y del mercado, el avance tecnológico, el surgimiento de las metrópolis y los procesos de globalización, entre otros, han tenido resultados paradójicos. Por un lado, se advierte un sostenido desarrollo material de gran parte de la población; la integración y participación de amplios sectores que por siglos se vieron excluidos de los procesos políticos, económicos y sociales, y el reconocimiento de garantías y derechos individuales. Pero, por otro lado, la aparición de nuevas formas de desigualdad social, el debilitamiento de espacios tradicionales de asociación y diversos conflictos derivados de una mayor diversidad social, entre otros, han generado sensaciones problemáticas y el temor a la posibilidad de fragmentación social.

No sorprende, entonces, que la cohesión social sea un tema central en la discusión de las ciencias sociales y en el debate político contemporáneo. ${ }^{4}$ La pregunta que sustenta esta reflexión puede formularse del modo siguiente: ¿Cómo es posible que sociedades cada vez más complejas y diferenciadas logren constituirse como una (relativa) unidad? Esta interrogante, tan difícil de responder de forma unívoca, no ha estado exenta de debates. Por de pronto, el concepto de cohesión social pone de manifiesto una de las principales paradojas de la modernidad. Por un lado, se observa una creciente valoración de la diversidad y la autonomía individual al interior de nuestras sociedades que entra en tensión con el componente coercitivo que implicaría la cohesión social. Pero, por otro, las tendencias disgregadoras de esta misma pluralidad han provocado efectos anómicos y han mostrado la consecuente necesidad que tiene toda comunidad política de encontrar el modo de permanecer unida para funcionar. Hacer compatibles ambas aspiraciones — unidad y diversidad - se ha convertido en un desafío contemporáneo fundamental.

En este sentido, parte importante del debate en torno a la cohesión social guarda relación con el contenido de esta categoría; es decir, respecto a los elementos en los que radicaría este mecanismo aglutinador. Pues si en las sociedades tradicionales, que se caracterizaban por su homogeneidad, este asunto parecía estar resuelto, en las sociedades modernas, construidas en torno a la diferencia y la pluralidad, el problema

${ }^{4}$ Sobre la evolución conceptual de la cohesión social, véase: Carlos Peña, "El concepto de cohesión social. Debates teóricos y usos políticos", en Redes, Estado y mercados. Soportes de la cohesión social latinoamericana, ed. Eugenio Tironi (Santiago: Uqbar Editores, 2008), 29-95. 
presenta mayores complejidades. ${ }^{5}$ En términos generales, existen dos grandes corrientes de interpretación en torno a este punto: la primera postula que el fundamento de la cohesión social residiría en las redes contractuales que surgen a partir de las preferencias y necesidades individuales y la interdependencia funcional de los sujetos; es decir, se trataría de un mecanismo más bien procedimental. ${ }^{6}$ La segunda, en cambio, enfatiza que es el conjunto de contenidos normativos — comunidad de fines y valores - lo que generaría un sentido de pertenencia entre los miembros de una determinada sociedad. ${ }^{7}$

Este ensayo se inscribe en esta última corriente interpretativa, aunque de un modo específico: desde la teoría del vínculo social, que ubica la cohesión social en la relación que se da entre los miembros de la sociedad, que permite generar redes de confianza y cooperación, y finalmente un proyecto compartido. ${ }^{8}$ En concreto, seguimos la tesis de la escuela inaugurada por el sociólogo chileno Pedro Morandé, y seguida por Eduardo Valenzuela y Carlos Cousiño, quienes señalan que en el caso de América Latina el vínculo social descansa primordialmente en el plano de la cultura; vale decir, en la experiencia del encuentro o en las relaciones comunitarias, antes que en el papel del Estado o del mercado. ${ }^{9}$ En este sentido, la copresencialidad, o el contacto social entre los diversos miembros de la sociedad, resultaría fundamental en la generación de vínculos de solidaridad y de pertenencia a algo "común", fenómeno que las relaciones basadas en la sola interdependencia funcional no alcanzan a concitar. ${ }^{10}$

${ }^{5}$ Sobre esta distinción, véase: Ferdinand Tönnies, Comunidad y sociedad (Buenos Aires: Losada, 1927).

${ }^{6}$ Herbert Spencer, The Man versus the State (Londres: Penguin Book, 1969).

${ }^{7}$ Emile Durkheim, La división del trabajo social (Madrid: Ediciones Akal, 2001).

${ }^{8}$ Esta tesis ha sido retomada por autores como Robert D. Putnam en Bowling Alone: The Collapse and Revival of American Community (Nueva York: Simon \& Schuster, 2000).

${ }^{9}$ Pedro Morandé, Cultura y modernización en América Latina (Santiago: IES, 2017); Carlos Cousiño y Eduardo Valenzuela, Politización y monetarización en América Latina (Santiago: IES, 2011); Eduardo Tironi y Sebastián Pérez Bannen, "La cohesión social latinoamericana", en Tironi, Redes, Estado y mercados, 377407.

${ }^{10}$ Guillermo Wormald et al., "Cultura de cohesión e integración en las ciudades chilenas”, Revista Invi 27, n. ${ }^{\circ} 76$ (2012): 120-122. 
Acá volvemos, entonces, al tema de la igualdad. Ésta sería uno de los aglutinadores normativos o simbólicos en los órdenes democráticos - como ya había afirmado Tocqueville en La democracia en América - ${ }^{11}$ facilitando un sentido de pertenencia, una comunidad de fines y valores, necesaria para la cohesión social. En palabras de Judith Maxwell: "La cohesión social implica construir valores compartidos y comunidades de interpretación, reducir las disparidades en riqueza e ingresos, y en general permitir a las personas tener la sensación de que están involucradas en una empresa común, enfrentando desafíos compartidos y que son miembros de la misma comunidad". ${ }^{12}$ Bajo esta perspectiva, los problemas de cohesión tendrían una importante relación - aunque en ningún caso unívoca - con la existencia de altos grados de desigualdad, lo que podría traducirse en una polarización de los grupos sociales, con todos los efectos disruptivos que ello implica. Siguiendo esta línea, el sociólogo Eduardo Valenzuela señala que una de las perspectivas fundamentales para observar la cohesión social remite al que sería el cimiento estructural de las sociedades democráticas, esto es, la equidad (o igualdad). ${ }^{13}$ Ésta última se entiende como la capacidad de la sociedad para distribuir de forma razonablemente equilibrada el poder y los distintos bienes sociales relevantes (materiales e inmateriales), mediante una serie de arreglos institucionales orientados a ese propósito; ${ }^{14}$ ello, de modo tal que se aseguren cierto nivel de bienestar y de cercanía entre todos sus miembros, que les permitan sentirse partícipes de un proyecto común.

El objetivo de este ensayo es introducir la relación entre igualdad y cohesión social en la comprensión del escenario actual de Chile. Proponemos que el cuestionamiento al "modelo" que se ha expandido en la sociedad chilena puede tener que ver, en parte, con la persistencia de

${ }^{11}$ Tocqueville, La democracia en América. vol. II, parte II, cap. 1.

12 Judith Maxwell, "Social Dimensions of Economic Growth", Eric J. Hansen Memorial Lecture Series 3, University of Alberta, January 25 (1996).

${ }^{13} \mathrm{Si}$ bien equidad e igualdad son conceptos distintos, creo que en este caso remiten al mismo contenido; es decir, a un equilibrio en la distribución de bienes y oportunidades y, por tanto, pueden ser utilizados como sinónimos.

${ }^{14}$ Eduardo Valenzuela, "Desorganización, solidaridad y movilidad", en Vinculos, creencias e ilusiones, ed. Eduardo Valenzuela et al. (Santiago: Uqbar, 2008), 17-60. Sobre la evolución del principio de igualdad en la historia moderna, véase: Pierre Rosanvallon, La sociedad de iguales (Buenos Aires: Ediciones Manantial, 2012). 
una desigualdad que el proceso de modernización, iniciado en dictadura y consolidado por la Concertación, no ha podido resolver. ${ }^{15}$ Así, a pesar del notable progreso en las condiciones de vida generales de la población, han permanecido formas de desigualdad y segmentación problemáticas para las generaciones que no ven cumplidas las aspiraciones que esa modernización prometió. Aunque los efectos de tal escenario sobre la cohesión social podrían observarse desde distintos ámbitos, este ensayo sigue la tesis de Christopher Lasch en La revolución de las elites, ${ }^{16}$ enfocándose principalmente en el potencial distanciamiento de las elites económicas ${ }^{17}$ del resto del entramado social. En el contexto de un importante crecimiento económico y de un discurso marcado de meritocracia, es posible observar una transformación en la estructura de la desigualdad, modificando la composición y la relación entre los diversos grupos sociales. Entre otros fenómenos, se percibe una alta concentración de "capital" — bienes materiales e inmateriales- en la elite económica chilena - que adquiere una preeminencia bajo el nuevo orden social centrado en el mercado-, que podría traducirse en un distanciamiento material y simbólico del resto de sus conciudadanos.

${ }^{15}$ Hablar de cuestionamiento no implica sostener que hay un rechazo al modelo, sino más bien que en la actualidad existe una mayor disposición a hacerle demandas al sistema, disposición que no existía antes. Aun así, sobre este punto hay puntos de vista opuestos. Entre quienes defienden el cuestionamiento crítico al modelo, aunque desde diferentes veredas políticas, véase Daniel Mansuy, Nos fuimos quedando en silencio (Santiago: IES, 2016), 133-135, y Giorgio Boccardo y Carlos Ruiz, Los chilenos bajo el neoliberalismo: Clases y conflicto social (Santiago: El Buen Aire S.A., 2014). Entre quienes critican esta tesis, véase Carlos Peña, Lo que el dinero si puede comprar (Santiago: Taurus, 2017).

${ }^{16}$ Christopher Lasch, The Revolt of the Elites and the Betrayal of Democracy (Nueva York: WW Norton \& Company, 1996).

17 Para efectos de este ensayo, la categoría de "elite económica" hace referencia a un grupo minoritario de personas que poseen categorías ocupacionales de empresarios, altos ejecutivos y profesionales, pero que, además, provienen de ciertos colegios tradicionales, cuentan con amplias redes sociales y son propietarios de algún medio de producción o diversos bienes inmuebles. Es decir, además de la riqueza, sus miembros participan de otros mecanismos de distinción estatutaria que otorgan el parentesco, pautas culturales, creencias y valores, estilos de vida, entre otros. La posición social de la elite, entonces, se relaciona tanto con aspectos materiales como simbólicos. Véase: Tak Wing Chan y John H. Goldthorpe, "Class and Status: The Conceptual Distinction and Its Empirical Relevance", American Sociological Review 72, n. ${ }^{\circ} 4$ (2007): 512-32; María Angélica Thumala, Riqueza y piedad: el catolicismo de la elite económica chilena (Santiago: Debate, 2007). 
Esto podría dificultar la posibilidad de construir y sentirse parte de un proyecto común, debilitando así los niveles de cohesión social.

El texto se divide en dos partes. La primera, sitúa el análisis en un marco teórico más amplio sobre la relevancia de la cohesión social y, siguiendo a Tocqueville, el impacto de los altos niveles de desigualdad sobre los vínculos sociales. Asimismo, se hace referencia a los desafíos que, en este sentido, los procesos de modernización capitalistas han supuesto. En particular, se pone énfasis en que posibles efectos de estas transformaciones económicas son el distanciamiento de las elites en distintos ámbitos y una baja interacción social entre los distintos grupos, que tienden a debilitar las normas de reciprocidad sobre las cuales se asienta la unidad de una determinada sociedad. Como veremos, acá no se sostiene que el distanciamiento sea un fenómeno nuevo, sino que ha adoptado nuevas formas, como producto de una estructura social distinta. Pero que, aun cuando se trate de un fenómeno histórico persistente, éste puede volverse más problemático en un contexto democrático con las aspiraciones meritocráticas que caracterizan a la sociedad contemporánea. La segunda parte se refiere concretamente al caso de Chile, que en las últimas décadas ha experimentado intensas transformaciones modernizadoras, no exentas de tensiones. Una de ellas es la persistente desigualdad en el acceso a los bienes socialmente relevantes - como intentaremos mostrar - y sus consecuencias en las formas de estratificación social, lo que podría traducirse en la disociación entre las elites económicas y el resto del entramado social, y su consecuente crisis de legitimidad.

\section{2. "SOCIEDAD DE MERCADO", DESIGUALDAD Y COHESIÓN SOCIAL}

En La democracia en América, Tocqueville advierte la siguiente paradoja: al mismo tiempo que la era moderna supone una mayor igualdad de condiciones - eso es justamente lo que le maravilla de la sociedad norteamericana-, uno de los peligros a los que tiende el modelo capitalista industrial es a formar una aristocracia en el seno de una democracia. En sus palabras, "así, a medida que la masa de la nación gira hacia la democracia, la clase particular que se ocupa de la industria se vuelve más aristocrática. Los hombres se muestran cada vez más semejantes en una y cada vez más diferentes en la otra, y la desigualdad aumenta en la pequeña sociedad en la misma proporción que decrece 
en la grande". ${ }^{18}$ De este modo, entre el empresario y el obrero - por ocupar sus propias categorías - puede llegar a formarse un abismo que los desvincule permanentemente, pues ya no existe nada en común entre ambos. ${ }^{19}$ Cuando se da ese supuesto, sólo permanecen unidos como eslabones extremos de una larga cadena que los hace mutuamente dependientes por sus intereses propios, pero sin un contacto - un vínculo real- entre sí. Por contraste, cuando existe mayor igualdad de condiciones, la semejanza entre los hombres - que permanecía escondida en las sociedades estamentales - se muestra de modo más patente, lo que facilita las relaciones y solidaridad mutua.

En atención a eso, Tocqueville insiste en cuidar que la desigualdad permanente de condiciones, propia del Antiguo Régimen, no se instale en las nuevas democracias. Con esto el pensador francés no se refiere a que deba existir una igualdad total o aritmética entre los miembros de una sociedad, sino, más bien, una que les permita verse y reconocerse entre sí como semejantes. Una "igualdad relacional", diría Rosanvallon, ${ }^{20}$ a través de un equilibrio de poder (cualquiera sea su fuente), en el que las diferencias no respondan a una jerarquía infranqueable, rígida y hereditaria, sino a aspectos circunstanciales, móviles y equitativos. De esta forma, continúa el argumento, nadie puede sentirse superior a los demás y concentrar una cuota tan importante de recursos de distinta índole, que le permita establecerse permanentemente en una posición de privilegio. A fin de cuentas, excesivos diferenciales de poder en una determinada configuración social pueden generar un distanciamiento y apartamiento de ciertos grupos, con las consecuentes tensiones al interior de la comunidad. ${ }^{21}$ Cuando esto sucede, se produce una pérdida de confianza y legitimidad en el orden establecido que debilita los niveles de cohesión social, a veces con altos grados de conflictividad.

Tocqueville señala, además, que en los órdenes sociales democráticos la concentración del dinero puede constituir un peligro para los

18 Tocqueville, La democracia en América, vol. II, parte II, cap. 20.

19 "Ni el primero se compromete a proteger ni el segundo a defender, y no están ligados de una manera permanente ni por el hábito ni por el deber. La aristocracia que instauran los negocios prácticamente nunca se establece en medio de la población industrial que dirige. Su objetivo no es gobernarla, sino servirse de ella". Ibídem, vol. II, parte II, cap. 20.

${ }^{20}$ Rosanvallon, La sociedad de iguales.

${ }^{21}$ Norbert Elias y John L. Scotson, Establecidos y marginados (México D.F: FCE, 2016). 
anhelos de igualdad que caracterizan a estas sociedades. Así, afirma que "en los países donde el dinero proporciona poder, la importancia de los hombres está en relación más o menos directa con las riquezas que poseen". ${ }^{22}$ Es decir, la riqueza se convierte en el fundamento más importante de los privilegios de la "nueva aristocracia".

Es justamente eso lo que advierte después, en el siglo XX, Karl Polanyi en La gran transformación, ${ }^{23}$ a propósito de los procesos de modernización capitalistas. ${ }^{24}$ En su análisis, el autor se detiene en los efectos desocializadores del establecimiento de una "sociedad de mercado" - distinta de una economía de mercado_- en la que el mercado y el dinero se convierten en el elemento rector de la vida social. ${ }^{25}$ Una

${ }^{22}$ Tocqueville, Igualdad social y libertad politica. Antología esencial, edición de Pierre Gibert (Barcelona: Página Indómita, 2015), 124.

${ }^{23}$ Karl Polanyi, La gran transformación (Madrid: FCE, 2003); Don Slater y Fran Tonkiss, Market Society: Markets and Modern Social Theory (Malden: Blackwell Publishers, 2001).

${ }^{24}$ La teoría social ha señalado distintos mecanismos como aquellos que caracterizan la modernización de la sociedad. Muchas veces estos mecanismos son complementarios, pero en ocasiones constituyen explicaciones del fenómeno que rivalizan entre sí. Así, se ha caracterizado la modernidad a partir de la especialización funcional, de la industrialización, de la burocratización y de la masificación social, entre otros. El énfasis que aquí se pone - porque correspondería al caso chileno, como veremos más adelante- es que la modernización puede ser descrita en algunos casos especialmente como un proceso de mercantilización, en el que el mercado y el dinero adquieren una centralidad para la integración que en otros contextos no posee.

${ }^{25}$ Polanyi distingue la sociedad de mercado de la economía de mercado, en cuanto los mecanismos económicos gestionan no sólo la economía, sino que también la mayor parte de los ámbitos de la vida civil. En este sentido, es necesario advertir que el mercado, por cierto, puede constituir una fuente de cohesión social. El mercado, en principio, ayuda a satisfacer necesidades básicas y producir bienestar generalizado, lo que implica mayores niveles de cohesión. También puede contribuir a generar expectativas de futuro, lo que motiva un esfuerzo conjunto por parte de todos los miembros de la sociedad para alcanzar determinadas metas. Asimismo, el mercado del trabajo, por ejemplo, es capaz de proveer de bienes materiales y emocionales a los individuos y, en ciertos casos, generar fuertes lazos de solidaridad entre ellos y las organizaciones. Sin embargo, el mercado también es capaz de producir efectos desintegradores; por ejemplo, cuando el mercado laboral es inseguro y excluyente; cuando no se recibe el retorno esperado por el esfuerzo; cuando el mercado ofrece bienes deseables pero inaccesibles a la mayor parte de la población, o cuando genera un sistema de estratificación percibido como cerrado, injusto o incapaz de proveer un desarrollo futuro. Véase: Nicolás Somma y Eduardo Valenzuela. "Las paradojas de la cohesión social en América Latina", Revista del CLAD Reforma y Democracia 61 (2015): 49-50. 
sociedad cuyas operaciones sociales se coordinan mayoritariamente a través de interacciones mercantiles pierde, según Polanyi, un aspecto esencial de la cohesión social: la comunidad de fines y valores. Se favorece la atomización de las relaciones sociales, los vínculos entre las personas pierden su contenido personal y comunitario, y se vuelven funcionales exclusivamente a intereses particulares.

Asimismo, si bien el establecimiento de una "sociedad de mercado" usualmente pone más dinero en poder de todas las personas, lo hace de manera que podría llegar a ser profundamente desigual, acentuando las distinciones basales entre los diversos sectores sociales y erosionando los niveles de integración. El mercado autorregulado, siendo una forma muy abstracta de coordinación de vínculos sociales, tiene, sin embargo, muchas dificultades para reunir toda la información relevante para una distribución equitativa de los bienes. ${ }^{26}$ En concreto, no considera las diferencias extramercantiles (producto de variables individuales, como las capacidades personales, y estructurales, como el nivel socioeconómico de origen), las que tienden a reproducirse a través del propio mercado.

Cabe agregar que la "colonización" del mercado de cada vez mayores ámbitos de la vida social ${ }^{27}$ permite que el dinero se convierta en el principio que determina el reparto de la inmensa mayoría de los bienes socialmente relevantes ${ }^{28}$-materiales y simbólicos-, o de las diversas formas de "capital", en términos de Bourdieu, sobre los cuales se basa nuestra configuración social. De este modo, quienes poseen más dinero suelen contar con los recursos necesarios, no sólo para

${ }^{26}$ Polanyi (La gran transformación) señala que de esto procede la necesidad de establecer límites sociales y políticos al mercado; vale decir, es justamente tarea de las instituciones sociales hacer visibles estas desigualdades y regularlas.

${ }^{27}$ Para Jürgen Habermas (Teoría de la acción comunicativa. Madrid: Taurus, 1999), si bien es cierto que la sociedad contemporánea puede describirse a partir de procesos de especialización funcional, es probablemente ingenuo desconocer que ello no desemboca aún en una sociedad "acéntrica", como postula Luhmann, porque ciertos mecanismos funcionales, como el dinero, la burocracia y el poder, tienden a colonizar ámbitos de la vida social que, a juicio de Habermas, sería deseable que estuvieran integrados mediante comunicaciones discursivas; es decir, a través de procesos de deliberación conscientes.

${ }^{28}$ Michael Sandel señala: "Mientras más capacidad adquisitiva tenga el dinero, mientras más pueda comprar, más relevante es la tenencia o falta de éste". Lo que el dinero no puede comprar (Madrid: Debate, 2013), 5. 
desplegar sus capacidades personales, sino también para participar en los distintos espacios de la vida comunitaria. Y a la inversa, quienes no están dotados monetariamente quedan en una posición de marcada exclusión, tanto de los asuntos públicos como de los bienes elementales para llevar una vida plenamente humana. Así, el costo que se pagaría por el incremento (dispar) de las condiciones de vida de las personas es una "dislocación social", ${ }^{29}$ en que las minorías privilegiadas pasarían a llevar una vida fundamentalmente ajena a la que desarrollan los demás grupos sociales.

De acuerdo a los autores que acá hemos seguido, el temor que expresaba Tocqueville no parece ser infundado: la desigualdad social en las democracias capitalistas, como en el caso de Estados Unidos, parece haber adoptado nuevas formas en lugar de resolverse. En concreto, pareciera que esta desigualdad se ha traducido — dada la alta concentración de capitales en la cúpula de la estructura social- en un excesivo distanciamiento de la elite del resto del entramado social, contradiciendo las expectativas democráticas.

\section{Desigualdad y distanciamiento de la elite económica}

De modo amplio, las elites pueden entenderse como aquellos grupos minoritarios determinantes en las decisiones estratégicas que configuran las condiciones de vida de una sociedad. ${ }^{30}$ Tal como explican las distintas perspectivas teóricas al respecto, desde la aproximación clásica formulada por Mosca y Pareto ${ }^{31}$ hasta nuestros días, ellas constituirían un fenómeno universal. Sin embargo, según el contexto histórico, las elites cambian su composición, así como también el sustento de su legitimidad y el modo en que se vinculan con el resto del entramado social, todo lo cual responde, entre otros aspectos, a los fundamentos simbólicos de una determinada sociedad. En este sentido, como es sabido, una las primeras pretensiones de la modernidad es que toda diferen-

\footnotetext{
${ }^{29}$ Polanyi, La gran transformación.
}

${ }^{30}$ Algunas aproximaciones actuales a la teoría de las elites pueden encontrarse en Michael Hartmann, The Sociology of Elites (Londres: Routledge, 2007); Shamus Khan, "The Sociology of Elites", Annual Review of Sociology 38, n. 1 (2012): 36177.

${ }^{31}$ Gaetano Mosca, La clase política (1896); Wilfredo Pareto, Auge y caída de las elites (1920). 
ciación social sea vista como contingente y no como un orden "natural" de la sociedad, ${ }^{32}$ que asigna a cada uno su rol en la estructura social. Las distinciones entre unos y otros dejan, por tanto, de responder a un fundamento adscriptivo, permitiendo que, en primera instancia, todos puedan reconocerse y relacionarse en cuanto iguales. ${ }^{33}$

Este principio está en la base del cuestionamiento que caracteriza a las elites contemporáneas, particularmente a las económicas, sobre las que se refiere este ensayo. La transformación económica de las democracias capitalistas no sólo no supuso una disminución de la desigualdad, sino que además consolidó a una elite que hoy aparece fuertemente deslegitimada. Esto, entre otras cosas, debido a una alta concentración de recursos sumada a una escasa movilidad social en su interior, semilla de un aislamiento progresivo que se expresa en formas de vida muy diferentes de las de la gran mayoría, pero también en el desinterés de la elite respecto de aquello que se define como lo "común", y que ha sido destacado ya por autores como Christopher Lasch y Charles Murray para el caso de Estados Unidos. ${ }^{34}$ Ésta es justamente la crítica detrás del famoso eslogan "somos el 99 por ciento", utilizado inicialmente por el movimiento estadounidense Occupy Wall Street el año 2011, y que se extendió por numerosos países para denunciar la indignación de la mayoría de la población frente al uno por ciento que determina la vida económica y política a través de un enorme control sobre los recursos del país, pero sin considerar los intereses comunes. ${ }^{35}$ El contexto institucional que dio al dinero un papel fundamental en la distribución de los bienes, articulándose como el principal coordinador de las relaciones sociales, habría sido también importante en el fortalecimiento de esta elite desvinculada de los demás grupos sociales.

32 Charles Taylor, Imaginarios sociales modernos (Barcelona: Paidós, 2006), 31.

33 "En un pueblo aristocrático, cada casta tiene sus opiniones, sentimientos, derechos, costumbres y existencia aparte. Así, los hombres que la componen en nada se parecen a todos los restantes, no tienen la misma forma de pensar ni de sentir y sólo difícilmente creen que forman parte de la misma humanidad". Tocqueville, La democracia en América, vol. II, parte III, cap. 1.

${ }^{34}$ Estados Unidos se vio afectado por un alza en sus niveles de desigualdad a partir de la década de los 80 .

35 Joseph E. Stiglitz, El precio de la desigualdad (Madrid: Taurus, 2015). 
Si lo anterior es plausible, en lugar de acercarse al resto de sus conciudadanos como parte del proceso democrático, pareciera que se mantiene una suerte de abismo entre las elites y el resto de los sectores sociales. Y si esto es así, proponemos, podría llegar a tener consecuencias sobre la posibilidad de construir un proyecto común, generando finalmente un debilitamiento de la cohesión social. Como advertimos en la introducción, este ensayo no sostiene que el distanciamiento sea un fenómeno nuevo ni tampoco mayor a otros momentos históricos, sino que ha adoptado nuevas formas, debido a la transformación del orden social. Si en las sociedades tradicionales, cuya estructura social se basaba en relaciones estamentales, el distanciamiento entre los grupos sociales se expresaba en términos de una rígida jerarquía y escasa movilidad social — conformando una "comunidad de desiguales", como diría José Bengoa- ${ }^{36}$ hoy podría decirse que la distancia se presenta más bien en términos de "capital" - en el sentido complejo del concepto que hemos seguido hasta el momento-, con implicancias tanto materiales como simbólicas. Esto se traduce, entre otras cosas, en la dificultad de generar experiencias compartidas y en un escaso interés por un bien común.

Charles Murray, por ejemplo, en su reciente libro Coming Apart, describe el surgimiento, durante los últimos 50 años, de una nueva clase alta en los Estados Unidos, que ha tendido a distanciarse del modo de vida norteamericano, hasta el punto de volverse culturalmente irreconocible para el ciudadano común y corriente. Se trata de un grupo más rico, con una alta formación universitaria y profesional, segregado $\mathrm{y}$ fuertemente endogámico. Pero, además, sostiene Murray, lo caracteriza una creciente ignorancia respecto del país que manejan. ${ }^{37}$ En esta línea, avanza la crítica de Christopher Lasch a la nueva elite formada en el contexto de las "sociedades de mercado". Para el autor de La revolución de las elites, si bien siempre han existido grupos privilegiados, estos nunca habían estado tan peligrosamente aislados de su alrededor, de la vida común de los ciudadanos, como en la actualidad. ${ }^{38}$

${ }^{36}$ José Bengoa, en Historia rural de Chile (Santiago: LOM Ediciones, 2015), elabora esta expresión para referirse a un tipo de estructura social que en Chile se daba de modo paradigmático en la hacienda.

${ }^{37}$ Charles Murray, Coming Apart: The State of White America, 1960-2010 (Nueva York: Three Rivers Press, 2013).

${ }^{38}$ Lasch, The Revolt, 3. 
Aunque el argumento pueda ser discutible, ${ }^{39}$ tiene su fundamento. Entre los factores que influyen en la desvinculación que se denuncia, se aprecian realidades características de la sociedad creada en las últimas décadas bajo las transformaciones económicas capitalistas. Así es posible mencionar, en primer lugar, el explosivo aumento de la riqueza en estos sectores. Esta acumulación de capital económico se torna problemática en la medida en que intensifica las divisiones sociales. ${ }^{40}$ En efecto, la distancia en términos de ingreso que se produce entre los percentiles superiores de la escala social con el resto de la población resulta bastante llamativa. El problema, sin embargo, no es sólo que los ricos tengan mucho dinero, sino que el dinero los aísle de la vida común. Y si esto es plausible, este distanciamiento no se expresa solamente en términos materiales - en la desigualdad de ingresos-, sino que también simbólicos, en la medida en que el capital económico permite, o por lo menos acentúa, la acumulación de otras formas de capital sobre las cuales se fundamenta la estratificación social, como el cultural y social. ${ }^{41}$

Así, las grandes diferencias socioeconómicas se traducen en múltiples ámbitos de la vida social. Por un lado, hay una marcada desigualdad de acceso a servicios básicos y oportunidades vitales que parecen estar restringidas a un sector minoritario de la sociedad. A esto se vincula la segregación espacial de los principales centros urbanos, que han reducido de modo dramático su capacidad de integración. ${ }^{42} \mathrm{La}$ experiencia de la ciudad parece ser radicalmente distinta para los habitantes de un sector y otro: muros materiales y simbólicos

39 Harry G. Frankfurt, On Inequality (Nueva Jersey: Princeton University Press, 2015); William Watson, The Inequality Trap: Fighting Capitalism Instead of Poverty (Toronto: University of Toronto Press, 2015).

${ }^{40}$ En el caso de América Latina, además, se ha instalado un modelo particular de mercado que Ross Schneider llama "capitalismo jerárquico"; esto es, una forma de capitalismo caracterizado por una profunda penetración de corporaciones multinacionales; grandes y diversificados conglomerados familiares; un mercado laboral segmentado, y un bajo nivel educativo. Ben Ross Schneider, Hierarchical Capitalism in Latin America (Cambridge: Cambridge University Press, 2013).

${ }^{41}$ Pierre Bourdieu, "Las formas del capital", en Poder, derecho y clases sociales (Bilbao: Desclée de Brouwer, 2001); Bourdieu, La distinción (Madrid: Taurus, 1988).

${ }^{42}$ Sobre este tema, véase: Mike Savage et al., Urban Sociology, Capitalism and Modernity (Hampshire: Palgrave, 2003). 
tienden a generar vidas desvinculadas, con intereses, preocupaciones, necesidades y anhelos muy distintos, y donde la posibilidad de encuentro y de contacto presencial con el otro en cuanto igual se reduce al mínimo en no pocas ocasiones. Asimismo, se percibe una diferenciación en el trato de acuerdo al estatus social de las personas, como también desigualdad en la participación e influencia en los diversos espacios de poder al interior de la sociedad. ${ }^{43}$ Estas desigualdades parecen reproducirse y perpetuarse a través de diversos mecanismos institucionales, culturales y estructurales, acentuando la sensación de injusticia. $^{44}$

Lasch sostiene, además, que la clase privilegiada actual ha perdido el sentido de responsabilidad cívica que había caracterizado a la elite tradicional, la que, afincada en un determinado lugar por generaciones, solía establecer vínculos más estables y un mayor compromiso con la comunidad local. ${ }^{45}$ La transnacionalización del mercado del capital y las tendencias globalizadoras han dado origen a una elite cosmopolita que ha trasladado las lealtades locales al plano internacional, al punto de que ésta pareciera tener más en común con las elites globales que con sus conciudadanos.

En definitiva, la modernización parece tener sus ambigüedades, expresadas, en el último tiempo, en este distanciamiento de la elite, el que la aparta de manera problemática de aquellas formas de vida y organización, experiencias, realidades y visiones compartidas por la mayoría

${ }^{43}$ Chan y Goldthorpe, "Class and Status".

${ }^{44}$ La percepción de injusticia guarda relación con el tipo de desigualdades que están o no legitimadas en el discurso social. En las sociedades democráticas capitalistas se espera que la posición de cada sujeto esté determinada por su trabajo y esfuerzo personal, y no por privilegios adquiridos. Es decir, opera un principio de justicia basado en la meritocracia. Sobre esto, véase la nota 43. Pero a esto hay que añadir que la legitimidad del sistema está vinculada también con lo que Elizabeth Anderson denomina la "igualdad democrática", donde todos los ciudadanos cuenten con los recursos mínimos necesarios para participar en la vida de la comunidad política y lograr un reconocimiento recíproco. Véase: Elizabeth Anderson, “¿Cuál es el punto de la igualdad?", en Igualitarismo: una discusión necesaria, ed. Javier Gallegos y Thomas Bullemore (Santiago: CEP, 2016), 45-104. En relación a esto, para el caso de Chile, véase: PNUD, Desiguales. Orígenes, cambios y desafios de la brecha social en Chile (Santiago: PNUD, 2017) 28-31; 223-254.

${ }^{45}$ Lasch, The Revolt, 4. 
de los ciudadanos. ${ }^{46} \mathrm{Y}$ al removerse de la vida común, difícilmente puede la elite comprender el país sobre el que ejerce su liderazgo. ${ }^{47}$ Este cuadro general ciertamente puede darse en mayor o menor grado dependiendo de la sociedad particular de que se trate. Nuestra tesis es que en el caso chileno las dificultades sugeridas se presentan de manera importante, tal como veremos a continuación.

\section{EL CASO CHILENO}

La transformación operada por la modernización capitalista de la sociedad chilena, y en concreto la transformación de las elites socioeconómicas del país, guarda algunas similitudes con los procesos globales descritos, aunque posee sus propias particularidades. El caso chileno es interesante, justamente, por ser un ejemplo paradigmático de modernización por vía del mercado. El modelo de desarrollo que se implantó desde mediados de la década de los 1970, durante el régimen de Pinochet, gracias al impulso de los Chicago Boys, y que se consolidó durante el periodo de la Concertación, ha sido caracterizado por varios

${ }^{46}$ A todo esto se suma un asunto que parece típicamente moderno, que es interesante tener en cuenta y es el hecho de que el discurso meritocrático parece legitimar la lógica imperante, y la posición de cada cual en la estructura social. Este discurso llevado al extremo, según Lasch, ha permitido a las elites desligarse de las obligaciones y responsabilidades que su posición les exige, desvinculándose aún más del resto de la sociedad. Véase, por ejemplo: Lasch, The Revolt, 37-44; Pierre Rosanvallon, La sociedad de iguales, 87. Sin embargo, ¿cuán ciertas son las creencias meritocráticas? Shamus Khan, en un trabajo etnográfico sobre la elite norteamericana (Privilege: The Making of an Adolescent Elite at St. Paul's School, Nueva Jersey: Princeton University Press, 2010), señala que ella olvida que las condiciones sociales que permiten gozar de ciertos privilegios están altamente vinculados a características adscriptivas - el origen social - más que meritocráticas. El problema es que subestimar las condiciones de posibilidad que permiten a una elite ocupar una alta posición social disminuye la disposición a contribuir (o retribuir) a la sociedad, por ejemplo, a través del pago de impuestos o la inversión en bienes públicos, y, sobre todo, naturaliza lo que Khan denomina "desigualdad democrática"; es decir, la idea de que las inequidades actuales responden a características personales y no a desventajas de origen, perpetuando un sistema que crea desigualdades permanentes.

${ }^{47}$ Murray, Coming Apart. 
autores $^{48}$ por un acentuado liberalismo económico que supuso una expansión del mercado como elemento central de integración social.

Este proceso no estuvo exento de tensiones políticas y sociales. ${ }^{49}$ El resultado del modelo establecido fue un notable crecimiento económico en Chile durante las últimas cuatro décadas. La significativa disminución de la pobreza y de los problemas asociados a ella, como el analfabetismo, la desnutrición, la indigencia; el aumento del bienestar material de amplios sectores de la población que hasta entonces se hallaban muy ajenos a él, y los buenos resultados en índices de medición como el PIB y el ingreso per cápita son indesmentibles. La incorporación de Chile al grupo de países de la OCDE es reflejo del avance sostenido que experimentó el país durante este periodo.

Sin embargo, en el último tiempo, se ha ido tomando también conciencia de la alta concentración de la riqueza en los percentiles superiores, ${ }^{50}$ que se manifiesta en elevados niveles de desigualdad y segregación social. ${ }^{51}$ Chile se ubica en el segundo lugar (después de México) en la lista de los índices de desigualdad de los países que

${ }^{48}$ Guillermo Wormald y Daniel Brieba, "Institutional change and development in Chilean market society", en Institutions Count: Their Role and Significance in Latin American Development, eds. Alejandro Portes y Lori D. Smith (University of California Press, 2012); Cousiño y Valenzuela, Politización y monetarización; Eduardo Valenzuela, La rebelión de los jóvenes (Santiago: Ediciones SUR, 1984).

${ }^{49}$ Este proceso de modernización modificó profundamente la sociedad chilena en su estructura y marco institucional. Fundamentalmente, se privatizaron importantes sectores y actividades económicas y sociales del país, como gran parte de la industria, la banca, la energía y el transporte aéreo. Algo semejante ocurrió con los servicios públicos (agua, gas, telefonía, electricidad), el sistema de seguridad social, la educación y la salud. Lo anterior hizo posible la extensión de la lógica mercantil, incluso hacia ámbitos que tradicionalmente eran ajenos a ella. Sobre visiones particulares de estos procesos y sus consecuencias, véase: Manuel Gárate, La revolución capitalista de Chile (1973-2003) (Santiago: Ediciones Universidad Alberto Hurtado, 2012); Pilar Vergara, Auge y caida del neoliberalismo en Chile (Santiago: Flacso, 1984); Boccardo y Ruiz, Los chilenos; Andrés Solimano, Capitalismo a la chilena y la prosperidad de las elites (Santiago: Catalonia, 2012).

50 Javier E. Rodríguez, Desarrollo y desigualdad en Chile (1850-2009). Historia de su economía política (Santiago: Dibam y Centro de Investigaciones Diego Barros Arana, 2017), 221-253.

${ }^{51}$ Un panorama global sobre la estructura de la desigualdad en Chile está en el estudio del PNUD, Desiguales. Un contrapunto a esta postura puede verse en Claudio Sapelli, Chile: ¿Más equitativo? Una mirada a la dinámica social del Chile de ayer, hoy y mañana (Santiago: Ediciones UC, 2016). 
conforman la OCDE, con un coeficiente de Gini de 0,$45 ; 52$ brechas salariales de 29 veces entre el primer y el último decil,${ }^{53}$ y donde la participación del 1 por ciento más rico del país es de 30,5 por ciento del ingreso total. ${ }^{54} \mathrm{Al}$ mismo tiempo, los datos de la encuesta Casen 2015 señalan que actualmente alrededor de 2 millones de chilenos no cuentan con un ingreso mínimo para suplir sus necesidades básicas, y que son más de 3,5 millones los que viven en una situación de pobreza multidimensional. Esto incluye factores relacionados con la vivienda, salud, educación, trabajo y seguridad social y redes. Además, la encuesta señala que 4 de cada 10 chilenos se encuentran en situación de vulnerabilidad; es decir, existe una alta tasa de entrada y salida de la pobreza y la indigencia. ${ }^{55}$

La desigualdad ha sido un problema endémico en Chile como en el resto de América Latina, y en este sentido cualquier idealización del pasado carece de sustento. ${ }^{56}$ Sin embargo, la transformación modernizadora de los años 80 tuvo sus propios efectos, cambiando la fisonomía de los distintos grupos sociales en Chile, los vínculos entre ellos y sus modos de relacionarse. Estos, como acabamos de señalar, de algún modo se vieron afectados por las diferencias socioeconómicas (y sus consecuencias materiales y simbólicas) que adquirieron una naturaleza distinta bajo el nuevo paradigma institucional. En efecto, la expansión del mercado y de la privatización de ciertos bienes públicos implicó, entre otras cosas, que las oportunidades, el acceso a ciertos bienes socialmente relevantes y la calidad de vida de los chilenos estén

52 Según los datos de la OCDE para el 2015. El cálculo es en base a ingresos por hogar equivalente (ajustado por tamaño del hogar) después de impuestos y transferencias. Disponible en: http://www.oecd.org/social/income-distributiondatabase.htm.

${ }^{53}$ Además, según los datos de la encuesta Casen 2015, el ingreso autónomo per cápita del quinto quintil es de $\$ 859.330$, triplicando el del quintil anterior y siendo casi 12 veces mayor que el del primero. Ministerio de Desarrollo Social, Informe de desarrollo social 2015, disponible en: http://www.ministeriodesarrollosocial.gob.cl/pdf/upload/IDS_INAL_FCM_3.pdf.

${ }^{54}$ Ramón López E. et al., "La 'parte del león': Nuevas estimaciones de la participación de los súper ricos en el ingreso de Chile", Serie de Documentos de Trabajo 379, Facultad de Economía y Negocios de la Universidad de Chile (2013).

${ }^{55}$ Ministerio de Desarrollo Social, Informe de desarrollo social 2015.

${ }^{56}$ PNUD, Desiguales, capítulo 3; Rodríguez, Desarrollo y desigualdad en Chile. 
determinados en un grado muy significativo por su capacidad de pago, acentuando el desequilibrio en las ventajas y desventajas entre un sector y otro de la población..$^{57}$ En el caso de la elite económica ${ }^{58}$ — que es la que nos interesa analizar en este artículo-, este nuevo sistema posibilitó la emergencia de un nuevo y potente liderazgo del mundo empresarial y tecnocrático, que se unió a la existente elite tradicional reconvertida desde la reforma agraria, y que comenzó a operar a partir de nuevas lógicas y códigos, propios de la transformación económica ocurrida. ${ }^{59}$

La modernización chilena de las últimas décadas a la que nos hemos referido en este apartado no sólo consolida esta fusión y cambia la composición de la elite económica, también, y tal vez más profundamente, contribuye a modificar sus prácticas sociales, la comprensión

${ }^{57}$ Las economías monetarias cambian significativamente las condiciones de vida de la población en general, pero esas transformaciones se producen a ritmos muy distintos, lo que genera un desequilibrio. Así, mientras en los grupos más aventajados perciben estos cambios de forma acelerada y casi inmediata, los menos aventajados demoran más tiempo en percibir estos beneficios, más aún cuando hay una distancia muy marcada entre unos y otros.

${ }^{58}$ Sobre cómo ha sido abordada la elite económica en Chile en la investigación social, véase el análisis de Jorge Atria et al. "Investigando a la élite económica: Lecciones y desafíos a partir del caso de Chile", Cultura-hombre-sociedad 27, n. ${ }^{\circ} 2$ (2017): 5-36. Este artículo caracteriza a la elite económica chilena como un grupo extremadamente liberal en lo económico, que percibe el mayor porcentaje de recursos entre países en que se ha estudiado la concentración de ingreso en la región y que se encuentra muy cohesionado, en especial a través de gremios empresariales, canalizando efectivamente sus intereses en distintas reformas y negociaciones con el sector público. Es también un grupo altamente clausurado en términos de movilidad social, homogéneo y relativamente conservador en términos religiosos, y concentrado geográficamente en un área bien delimitada de la capital. También resultan interesantes los libros de Pedro Güell y Alfredo Joignant, Notables, tecnócratas y mandarines: elementos de sociología de las elites en Chile (1990-2010) (Santiago: Ediciones Universidad Diego Portales, 2011) y el ya mencionado de Thumala, Riqueza y piedad.

59 Zeitlin y Ratcliff, en su obra Landlords and Capitalists: The Dominant Class of Chile (Nueva Jersey: Princeton University Press, 1988), se refieren a los orígenes de la estructura interna de esta elite socioeconómica. El proceso se inicia a mediados del siglo XX, mediante el ensamblaje entre dos sectores estratégicos: la elite hacendada tradicional y el nuevo empresariado industrial, a través de vínculos económicos y de los lazos de parentesco. Esta fusión de redes e intereses económicos y sociales permitió a las familias que constituían esta unidad social no sólo la acumulación de altos grados de poder económico, político y social, sino que también su reproducción y afianzamiento como grupo. 
de sí misma y el entendimiento de su función social, dando origen a un nuevo ethos o "modo de ser". 60

\section{Desigualdad y distanciamiento de la elite económica en Chile}

Como ya hemos señalado, en un contexto de mercantilización como sería el caso de Chile, el dinero adquiere una gran centralidad en la vida social, permitiendo el acceso a otro tipo de bienes relevantes, de orden tanto material como simbólico. Una distribución muy desigual del capital económico se traduce en un acceso también desigual a otros "capitales" relevantes de índole cultural, social y simbólica, ${ }^{61}$ y sobre los cuales se basa la estructura social. El problema, como apuntamos en este trabajo siguiendo la tesis de Lasch, es que la concentración de estos capitales genera formas de desigualdad que permiten que los grupos más aventajados se distancien y desvinculen del resto del entramado social, llevando vidas completamente ajenas a las de sus conciudadanos, y erosionando los niveles de cohesión social.

Veamos cómo en ciertos ejemplos de desigualdad en Chile pueden reconocerse potenciales distanciamientos de la elite.

La acumulación y concentración de las riquezas supone un problema no menor: a las cifras citadas anteriormente, que señalan que el 1 por ciento más rico del país concentra más de un cuarto del ingreso total, se suma el dato de que el diez por ciento de mayores ingresos recibe el 47 por ciento del total, mientras que el 20 por ciento inferior cuenta sólo con el 3,4 por ciento. ${ }^{62}$ No se trata solamente de un problema de desigualdad material, sino que también de la potencial dificultad

${ }^{60}$ Luis Barros y Ximena Vergara, El modo de ser aristocrático: el caso de la oligarquía chilena hacia 1900 (Santiago: Aconcagua, 1978). Las diferencias entre la "elite tradicional" y la que se formó en este periodo pueden observarse en el notable trabajo de María Rosaria Stabili, El sentimiento aristocrático. Elites chilenas frente al espejo (1860-1960) (Santiago: Editorial Andrés Bello, 2003).

${ }^{61}$ Bourdieu, La distinción; Bourdieu, "Las formas del capital". En el caso del capital simbólico, Bourdieu lo define como el prestigio o estatus asociado a ciertas características.

${ }^{62}$ Claudia Sanhueza y Ricardo Mayer, "Top Incomes in Chile Using 50 Years of Household Surveys: 1957-2007”, Estudios de Economía 38, n. ${ }^{\circ} 1$ (2011): 169-93, y Tasha Fairfield y Michel Jorratt, "Top Income Shares, Business Profits, and Effective Tax Rates in Contemporary Chile", Review of Income and Wealth 62 (2016): S120-S144. 
de integración social derivada de tales niveles de diferencia. Los efectos políticos de este fenómeno son advertidos por Daniel Mansuy: “¿Qué comunidad efectiva puede haber allí donde hay tanta diferencia? ¿Qué tipo de acción común, qué tipo de política, puede fundarse desde distancias tan marcadas? ¿Qué soporte tiene esa comunidad para enfrentar una crisis grave?"63 A pesar de compartir un territorio común, muchas veces pareciera que vivimos en países distintos, con experiencias muy disímiles, y eso tiene sus consecuencias.

La riqueza permite, a su vez, el acceso a otro tipo de capital fundamental que es la educación, y que, como ha sido destacado en diversas investigaciones sobre estratificación social, ${ }^{64}$ actualmente constituye un elemento central de distinción y reproducción de las elites. De este modo, si bien la educación es considerada como un medio de movilidad social, paradójicamente ella resulta ser, al mismo tiempo, un mecanismo de distinción y jerarquización muy relevante. La acentuada segregación y segmentación del sistema escolar chileno contribuye a la mantención y reproducción intergeneracional de la elite socioeconómica. ${ }^{65}$ A través de estas exclusivas instituciones, sus miembros obtienen no sólo competencias y resultados académicos relevantes para un buen desempeño profesional, sino también redes de contacto, espacios de socialización y códigos éticos, estéticos y conductuales. Estos últimos constituyen una fuente importante de estatus y prestigio - capital social y simbólico-, que identifica a la elite como grupo a la vez que la diferencia de los demás, y hace más probable la obtención de altas posiciones de influencia en distintos ámbitos. ${ }^{66}$

${ }^{63}$ Mansuy, Nos fuimos quedando, 134.

${ }^{64}$ Emilio Moya y Javier Hernández, "El rol de los colegios de elite en la reproducción intergeneracional de la elite chilena", Revista Austral de Ciencias Sociales 26 (2014): 59-82; Sebastián Madrid, “Diversidad sin diversidad”: Los colegios particulares pagados de elite y la formación de la clase dominante en una sociedad de mercado", en Mercado escolar y oportunidad escolar: libertad, diversidad y desigualdad, ed. Javier Corvalán et al. (Santiago: Ediciones UC, 2016), 269-300.

65 Juan Pablo Valenzuela et al. "Segregación escolar en Chile", en ¿Fin de ciclo? Cambios en la gobernanza del sistema educativo, ed. Sergio Martinic y Gregory Elacqua (Santiago: Pontificia Universidad Católica de Chile y Unesco, 2010), 209-229.

${ }^{66}$ Ibídem. 
Este escenario no es exclusivo del nivel escolar. Algo similar sucede con las universidades. Aunque en ellas hay más diversidad, y los datos muestran que contribuyen a la movilidad social, también es posible observar que el origen social influye de forma relevante en las posibilidades de éxito en el acceso, en el desempeño y en el resultado en el proceso de obtener un título. ${ }^{67}$ Así, el ingreso al sistema universitario no está desligado del origen socioeconómico de los estudiantes, impidiendo resolver el problema de la segregación y que se traduce en la producción y reproducción de otras desigualdades en los niveles de empleabilidad, rentas y oportunidades de trayectoria profesional. ${ }^{68}$ Un trabajo de Seth Zimmerman, economista de la Universidad de Chicago, deja en evidencia el efecto que ejercen el origen familiar, el colegio y la universidad en las oportunidades de formar parte de la elite empresarial y económica en Chile. ${ }^{69} \mathrm{La}$ investigación revela cómo el hecho de ingresar a derecho, ingeniería comercial o ingeniería civil en la Universidad de Chile o en la Universidad Católica aumenta en 50 por ciento las posibilidades de obtener una posición de liderazgo en el mundo empresarial (altos cargos ejecutivos o gerenciales, o una posición en el directorio); pero sólo si, además, fueron alumnos de algún colegio privado de elite. ${ }^{70}$ En definitiva, el autor señala que, al momento de postular a un alto cargo en el mundo de los negocios, tanto o más importante como la formación académica y la adquisición de ciertas competencias es el capital social que adquieren tempranamente los miembros de una elite que tiende a ser muy selectiva, a través de

${ }^{67}$ Sergio Urzúa, "Rentabilidad de la educación superior en Chile", Estudios Públicos 125 (2012): 1-43; Óscar Espinoza y Luis Eduardo González, "Equidad en el sistema de educación superior de Chile: acceso, permanencia, desempeño y resultados", en La educación superior de Chile: Transformación, desarrollo y crisis, ed. Andrés Bernasconi (Santiago: Ediciones UC, 2015), 519--578.

${ }^{68}$ Núñez y Gutiérrez, por ejemplo, han estudiado cómo el origen social puede ser un factor determinante en el mercado laboral, manifestándose concretamente en la brecha de sueldos de los trabajadores, a pesar de contar con la misma certificación académica: Javier Núñez y Roberto Gutiérrez, "Class Discrimination and Meritocracy in the Labor Market: Evidence from Chile", Estudios de Economía 31, n. ${ }^{\circ} 2$ (2004): 113-32.

${ }^{69}$ Seth Zimmerman, "Making Top Managers: The Role of Elite Universities and Elite Peers", manuscrito no publicado, Yale University (2013).

${ }^{70}$ Por colegios de elite se comprende en este estudio a los siguientes establecimientos: el St. George, The Grange, Verbo Divino, Manquehue, Tabancura, San Ignacio de El Bosque y el Craighouse. 
una red de contactos y vínculos personales que, sin ser determinante, condiciona, en un grado no menor, una trayectoria profesional exitosa y una alta posición social.

El lugar de residencia, como parte del capital económico, se convierte también en un factor importante de distinción social. Esto tiene como correlato altos grados de segregación urbana — principalmente en Santiago-, lo que constituye, tal vez, el indicio más patente de la potencial fragmentación social en la capital. Las diferencias en la calidad de vida son sustantivas: la calidad del barrio y de la vivienda; ${ }^{71}$ el nivel de las prestaciones de salud, ${ }^{72}$ seguridad social y educación; en suma, la posibilidad de acceder a ciertos bienes sociales relevantes que exigen un alto nivel de ingresos evidencia que la separación entre ambos sectores no es solamente física, sino que además se expresa en las formas de vida, percepciones, preocupaciones e intereses. En definitiva, la segregación espacial de algún modo explica y manifiesta otras formas de apartamiento social, económico, político y cultural; distanciamiento que puede ser especialmente problemático en una sociedad democrática, al erosionar los mecanismos de cohesión social.

El informe Desarrollo humano en Chile (2015), elaborado por el PNUD, da cuenta de ese múltiple distanciamiento. Así, por ejemplo, mientras que el 45 por ciento de la ciudadanía considera que es necesario que las cosas en el país cambien radicalmente, sólo el 19 por ciento de la elite piensa lo mismo. ${ }^{73}$ En cuanto a la participación del mercado en la vida social, el 59 por ciento manifiesta que no debería permitirse que las empresas privadas hagan negocios u obtengan ganancias en áreas como la salud, la educación y los servicios básicos; al mismo tiempo que ese mismo porcentaje aboga por una mayor presencia estatal en estos ámbitos. ${ }^{74}$ Además, a diferencia de lo que podría creerse, no

${ }^{71}$ Sobre el tema de la segregación espacial, véase, por ejemplo: Francisco Sabatini et al., "Segregación residencial en las principales ciudades chilenas: Tendencias de las tres últimas décadas y posibles cursos de acción", EURE 27, n. ${ }^{\circ} 82$ (2001): 21-42; Claudio A. Agostini et al., "Segregación residencial de ingresos en el Gran Santiago, 1992-2002: una estimación robusta", EURE 42, n. 127 (2016).

${ }^{72}$ El sistema de salud actual, compuesto por dos subsistemas, ha desarrollado un modelo altamente segregado, en el que el nivel y calidad de las prestaciones que recibe cada persona dependen de sus recursos económicos individuales.

73 PNUD, Desarrollo humano en Chile. Los tiempos de la politización (2015), 212.

${ }^{74}$ Ibídem, 213. 
es la desigualdad de ingresos la que genera mayor molestia en la ciudadanía (aunque no deja de ser relevante), sino cuestiones relacionadas pero no necesariamente dependientes de ella, como la desigualdad en el trato, ventajas y privilegios que se generan a partir de ella. ${ }^{75}$

Estas diferencias se profundizan aún más si consideramos que en Chile existe una baja movilidad social desde y hacia el estrato superior. Las posiciones extremas de la estructura social están más distanciadas y aisladas del resto. ${ }^{76}$ En este sentido, Florencia Torche señala que el caso chileno "puede verse como la combinación de dos regímenes de desigualdad y movilidad distintos. La alta concentración de recursos económicos determina fuertes barreras a la movilidad entre la elite y los sectores bajos, y una distribución de los recursos más igualitaria entre las clases medias y bajas resulta en una mayor fluidez entre ellas". ${ }^{77}$ En otras palabras, la estructura social se configura en torno a un estrato superior relativamente hermético, persistente y distante a la vez del resto del entramado social que es mucho más uniforme en su composición. Escenario semejante al descrito por Lasch en La rebelión de las elites.

Torche destaca la gran capacidad de reproducción intergeneracional de la elite a través de la herencia, que lega el patrimonio material y simbólico —riqueza y estatus-, y los lazos de parentesco. ${ }^{78}$ La relevante presencia de mecanismos adscriptivos en la estratificación social en Chile se traducen en una baja movilidad hacia y desde la elite que perpetúa la desigualdad:

En una sociedad muy desigual, los incentivos de la movilidad son altos para todos, pero los recursos necesarios para actualizarlos están tan desigualmente distribuidos que la competencia

\footnotetext{
${ }^{75}$ Rodrigo Márquez, "La distancia entre la ciudadanía y las elites. Una mirada desde el informe Desarrollo humano en Chile", Estudios Públicos 140 (2015): 83106.

${ }^{76}$ Vicente Espinoza et al., "Estratificación y movilidad social bajo un modelo neoliberal: el caso de Chile", Revista Lavboratorio 25 (2013): 169-91.

${ }^{77}$ Florencia Torche, "Desigual pero fluido: El patrón chileno de movilidad en perspectiva comparada", Expansiva 57 (2005): 19.

${ }^{78}$ Ibídem. Sobre este tema, véase también: Sebastián Huneeus, Matrimonio y patrimonio: estrategias matrimoniales de la elite chilena en el siglo XXI (Santiago: Uqbar Editores, 2013).
} 
beneficiará necesariamente a aquellos con orígenes sociales aventajados. El resultado de alta desigualdad será entonces la rígida reproducción de la estructura social, por tanto, una baja movilidad social. ${ }^{79}$

\section{CONCLUSIÓN}

En su obra Politización y monetarización en América Latina, Eduardo Valenzuela y Carlos Cousiño profundizan en la importancia del encuentro. Es decir, de que el vínculo social esté fundado, al menos en parte, en la experiencia común entre las personas. En este sentido, sostienen que "toda sociedad necesita de medios de integración no contractuales: cualquier pretensión que ignora la experiencia como esfera vinculante está condenada a producir un remedo de sociedad, una ficción que es contradicha permanentemente por la realidad". ${ }^{80}$ Es indudable que nuestras complejas sociedades modernas se articulan, de cierto modo, en torno a las diferencias funcionales y las relaciones contractuales; sin embargo, el contrato no constituye el punto de partida de la vida social, pues no alcanza a sostener el vínculo entre sus miembros, que en el ethos latinoamericano ha descansado históricamente en la "presencia", aunque de modos distintos.

Recordar esta tesis puede ser importante, pues el encuentro, la posibilidad del reconocimiento mutuo, sigue siendo fundamental en las sociedades democráticas, las que, como dijimos, sustentan su legitimidad en la convivencia entre ciudadanos que son considerados y se relacionan como iguales. La igualdad es una de las características distintivas de la modernidad: "La igualdad entendida como relación; como la vitalidad de una experiencia compartida, como una cualidad de proximidad, como una facilidad de intercambio". ${ }^{81}$ De ahí que los altos niveles de desigualdad se vuelvan más significativos que en otros contextos y se expliciten como problemáticos, pues ellos impiden justamente la configuración de ese espacio común. Si para los grupos más pobres la desigualdad puede significar grados de exclusión social y marginalidad, para las elites se ha traducido en la concentración de ventajas y privi-

\footnotetext{
79 Torche, "Desigual pero fluido", 5.

${ }^{80}$ Cousiño y Valenzuela, Politización y monetarización, 196.

${ }^{81}$ Rosanvallon, La sociedad de iguales, 52.
} 
legios, y en un distanciamiento que, como acá hemos querido esbozar, puede desafiar los fundamentos de la cohesión social. En última instancia, las elites son influyentes en las decisiones estratégicas del país, lo que hace que su distanciamiento sea especialmente problemático.

En definitiva, lo que este ensayo quiere mostrar es que la desigualdad en Chile tiene implicancias no sólo en el plano de la justicia, sino también en el de la articulación de esa vida compartida tan esencial para las sociedades democráticas.

\section{BIBLIOGRAFÍA}

Agostini, Claudio A., Daniel Hojman, Alonso Román \& Luis Valenzuela. "Segregación residencial de ingresos en el Gran Santiago, 1992-2002: una estimación robusta". EURE 42, n. ${ }^{\circ} 127$ (2016). http://www.eure.cl/index.php/ eure/article/view/1732/951

Anderson, Elizabeth. “¿Cuál es el punto de la igualdad?”. En Igualitarismo: una discusión necesaria, editado por Javier Gallegos \& Thomas Bullemore, 45104. Santiago: CEP, 2016.

Atria, Jorge, Josefina Amenábar, Javiera Sánchez, Juan Carlos Castillo \& Matías Cociña. "Investigando a la élite económica: Lecciones y desafíos a partir del caso de Chile". Cultura-hombre-sociedad 27, n. ${ }^{\circ} 2$ (2017): 5-36.

Barros, Luis \& Ximena Vergara. El modo de ser aristocrático: el caso de la oligarquía chilena hacia 1900. Santiago: Aconcagua, 1978.

Bengoa, José. Historia rural de Chile. Santiago: LOM Ediciones, 2015.

Boccardo, Giorgio \& Carlos Ruiz. Los chilenos bajo el neoliberalismo: Clases y conflicto social. Santiago: El Buen Aire S.A., 2014.

Bourdieu, Pierre. La distinción. Madrid: Taurus, 1988.

. Poder, derecho y clases sociales. Bilbao: Desclée de Brouwer, 2001.

Chan, Tak Wing \& John H. Goldthorpe. "Class and Status: The Conceptual Distinction and Its Empirical Relevance". American Sociological Review 72, n. ${ }^{\circ} 4$ (2007): 512-32.

Cousiño, Carlos \& Eduardo Valenzuela. Politización y monetarización en América Latina. Santiago: IES, 2011.

Durkheim, Emile. De la división del trabajo social. Buenos Aires: Schapire, 1967.

Elias, Norbert \& John L. Scotson. Establecidos y marginados. México D.F.: FCE, 2016.

Espinoza, Óscar \& Luis Eduardo González. "Equidad en el sistema de educación superior de Chile: acceso, permanencia, desempeño y resultados". En La educación superior de Chile: Transformación, desarrollo y crisis, editado por Andrés Bernasconi, 519-578. Santiago: Ediciones UC, 2015. 
Espinoza, Vicente, Emmanuelle Barozet \& María Luisa Méndez. "Estratificación y movilidad social bajo un modelo neoliberal: el caso de Chile". Revista Lavboratorio 25 (2013): 169-91.

Fairfield, Tasha \& Michel Jorratt. "Top Income Shares, Business Profits, and Effective Tax Rates in Contemporary Chile". Review of Income and Wealth 62 (2016): S120-S144.

Frankfurt, Harry G. On inequality. Nueva Jersey: Princeton University Press, 2015.

Gárate, Manuel. La revolución capitalista de Chile (1973-2003). Santiago: Ediciones Universidad Alberto Hurtado, 2012.

Güell, Pedro \& Alfredo Joignant. Notables, tecnócratas y mandarines: elementos de sociología de las elites en Chile (1990-2010). Santiago: Ediciones Universidad Diego Portales, 2011.

Habermas, Jürgen. Teoría de la acción comunicativa. Madrid: Taurus, 1999.

Hartmann, Michael. The Sociology of Elites. London: Routledge, 2007.

Huneeus, Sebastián. Matrimonio y patrimonio: estrategias matrimoniales de la elite chilena en el siglo XXI. Santiago: Uqbar, 2013.

Khan, Shamus Rahman. Privilege: The Making of an Adolescent Elite at St. Paul's School. Nueva Jersey: Princeton University Press, 2010.

—. "The Sociology of Elites". Annual Review of Sociology 38, n. ${ }^{\circ} 1$ (2012): 361-77.

Lasch, Christopher. The Revolt of the Elites and the Betrayal of Democracy. Nueva York: WW Norton \& Company, 1996.

López E., Ramón, Eugenio Figueroa B. \& Pablo Gutiérrez C. "La 'parte del león': Nuevas estimaciones de la participación de los súper ricos en el ingreso de Chile". Serie de Documentos de Trabajo 379, Facultad de Economía y Negocios de la Universidad de Chile (2013).

Madrid, Sebastián. “'Diversidad sin diversidad': Los colegios particulares pagados de elite y la formación de la clase dominante en una sociedad de mercado". En Mercado escolar y oportunidad escolar: libertad, diversidad y desigualdad, editado por Javier Corvalán, Alejandro Carrasco \& J.E. García-Huidobro, 269-300. Santiago: Ediciones UC, 2016.

Mansuy, Daniel. Nos fuimos quedando en silencio. Santiago: IES, 2016.

Márquez, Rodrigo. "La distancia entre la ciudadanía y las elites: una mirada desde el informe Desarrollo humano en Chile". Estudios Públicos 140 (2015): 83-106.

Maxwell, Judith. "Social Dimensions of Economic Growth". Eric J. Hansen Memorial Lecture Series 3, University of Alberta, January 25 (1996).

Ministerio de Desarrollo Social. Informe de desarrollo social 2015. http://www. ministeriodesarrollosocial.gob.cl/pdf/upload/IDS_INAL_FCM_3.pdf.

Morandé, Pedro. Cultura y modernización en América Latina. Santiago: IES, 2017.

Mosca, Gaetano. La clase política. 1896.

Moya, Emilio \& Javier Hernández. "El rol de los colegios de elite en la reproducción intergeneracional de la elite chilena". Revista Austral de Ciencias Sociales 26 (2014): 59-82. 
Murray, Charles. Coming Apart: The State of White America, 1960-2010. Nueva York: Three Rivers Press, 2013.

Núñez, Javier \& Roberto Gutiérrez. "Class Discrimination and Meritocracy in the Labor Market: Evidence from Chile”. Estudios de Economía 31, n. ${ }^{\circ} 2$ (2004): 113-32.

Ossandón, José, "Hacia una cartografía de la élite corporativa en Chile". En Adaptación. La empresa chilena después de Friedman, editado por José Ossandón \& Eugenio Tironi, 29-54. Santiago: Universidad Diego Portales, 2013.

Pareto, Wilfredo. Auge y caida de las elites. 1920.

Peña, Carlos. Lo que el dinero sí puede comprar. Santiago: Taurus, 2017.

PNUD. Desarrollo humano en Chile. Los tiempos de la politización. 2015.

Desiguales. Orígenes, cambios y desafios de la brecha social en Chile. Santiago: PNUD, 2017.

Polanyi, Karl. La gran transformación. Madrid: FCE, 2003.

Putnam, Robert D. Bowling Alone: The Collapse and Revival of American Community. Nueva York: Simon \& Schuster, 2000.

Rodríguez, Javier E. Desarrollo y desigualdad en Chile (1850-2009). Historia de su economía politica. Santiago: Dibam y Centro de Investigaciones Diego Barros Arana, 2017.

Rosanvallon, Pierre. La sociedad de iguales. Buenos Aires: Ediciones Manantial, 2012.

Sabatini, Francisco, Gonzalo Cáceres \& Jorge Cerda. "Segregación residencial en las principales ciudades chilenas: Tendencias de las tres últimas décadas y posibles cursos de acción". EURE 27, n. ${ }^{\circ} 82$ (2001): 21-42.

Sandel, Michael. Lo que el dinero no puede comprar. Madrid: Debate, 2013.

Sanhueza, Claudia \& Ricardo Mayer. "Top Incomes in Chile Using 50 Years of Household Surveys: 1957-2007”. Estudios de Economía 38, n. ${ }^{\circ} 1$ (2011): 16993.

Sapelli, Claudio. Chile: ¿Más equitativo? Una mirada a la dinámica social del Chile de ayer, hoy y mañana. Santiago: Ediciones UC, 2016.

Savage, Mike, Alan Warde \& Kevin Ward. Urban Sociology, Capitalism and Modernity. Hampshire: Palgrave, 2003.

Schneider, Ben Ross. Hierarchical Capitalism in Latin America. Cambridge: Cambridge University Press, 2013.

Slater, Don \& Fran Tonkiss. Market Society: Markets and Modern Social Theory. Malden: Blackwell Publishers, 2001.

Solimano, Andrés. Capitalismo a la chilena y la prosperidad de las elites. Santiago: Catalonia, 2012.

- Elites económicas, crisis y el capitalismo del siglo XXI. La alternativa de la democracia económica. Santiago: FCE, 2015. 
Somma, Nicolás \& Eduardo Valenzuela. "Las paradojas de la cohesión social en América Latina”. Revista del CLAD Reforma y Democracia 61 (2015): 43-74.

Spencer, Herbert. The Man versus the State. Londres: Penguin Book, 1969.

Stabili, María Rosaria. El sentimiento aristocrático: elites chilenas frente al espejo (1860-1960). Santiago: Editorial Andrés Bello, 2003.

Stiglitz, Joseph E. El precio de la desigualdad. Madrid: Taurus, 2015.

Taylor, Charles. Imaginarios sociales modernos. Barcelona: Paidós, 2006.

Thumala, María Angélica. Riqueza y piedad: el catolicismo de la elite económica chilena. Santiago: Debate, 2007.

Tironi, Eugenio. Redes, Estado y mercados. Soportes de la cohesión social latinoamericana. Santiago: Uqbar Editores, 2008.

Tocqueville, Alexis de. La democracia en América. Madrid: Ediciones Akal, 2007.

. Igualdad social y libertad política. Antología esencial. Edición de Pierre Gibert. Barcelona: Página Indómita, 2015.

Tönnies, Ferdinand. Comunidad y sociedad. Buenos Aires: Losada, 1927.

Torche, Florencia. "Desigual pero fluido: El patrón chileno de movilidad en perspectiva comparada". Expansiva 57 (2005).

_. "Movilidad intergeneracional y desigualdad: el caso latinoamericano". Annual Review of Sociology 40 (2014): S2-1.

Urzúa, Sergio. "Rentabilidad de la educación superior en Chile". Estudios Públicos 125 (2012): 1-43.

Valenzuela, Eduardo. La rebelión de los jóvenes. Santiago: Ediciones SUR, 1984.

Valenzuela, Eduardo, Simon Schwartzman, Andrés Biehl \& J. Samuel Valenzuela. Vinculos, creencias e ilusiones. Santiago: Uqbar, 2008.

Valenzuela, Juan Pablo, Cristián Bellei y Danae de Los Ríos. "Segregación escolar en Chile”. En ¿Fin de ciclo? Cambios en la gobernanza del sistema educativo, editado por Sergio Martinic \& Gregory Elacqua, 209-229. Santiago: Pontificia Universidad Católica de Chile y Unesco, 2010.

Vergara, Pilar. Auge y caída del neoliberalismo en Chile. Santiago: Flacso, 1984.

Watson, William. The Inequality Trap: Fighting Capitalism Instead of Poverty. Toronto: University of Toronto Press, 2015.

Wormald, Guillermo \& Daniel Brieba. "Institutional change and development in Chilean market society". En Institutions Count: Their Role and Significance in Latin American Development, editado por Alejandro Portes \& Lori D. Smith, 60-84. Berkeley y Los Angeles: University of California Press, 2012.

Wormald, Guillermo, Francisco Sabatini, Alejandra Rasse \& María Paz Trebilcok. "Cultura de cohesión e integración en las ciudades chilenas", Revista Invi 27, n. ${ }^{\circ}$ 76, (2012): 117-145.

Zeitlin, Maurice \& Richard Earl Ratcliff. Landlords and Capitalists: The Dominant Class of Chile. Nueva Jersey: Princeton University Press, 1988.

Zimmerman, Seth. "Making Top Managers: The Role of Elite Universities and Elite Peers". Manuscrito sin publicar, Yale University (2013). EP 
